Año 13.

Revista de Investigación

Académica sin Frontera

Núm. 34 Especial Tema COVID 19

ISSN: 2007-8870

https://revistainvestigacionacademicasinfrontera.unison.mx/index.php/RDIASF

Recibido el 19 de marzo de 2020. Dictaminado mediante arbitraje favorablemente 2 de julio de 2020.

\title{
EL COVID-19 Y SUS CONSECUENCIAS EN LA ADMINISTRACIÓN DE JUSTICIA.
}

\author{
Ana Edith Canales Murillo ${ }^{1}$ \\ https://orcid.org/0000-0003-3361-7923 \\ Erick Eduardo Galarza Loya ${ }^{2}$ \\ https://orcid.org/0000-0002-6288-7044.
}

\section{Resumen}

Actualmente el tema sobre la epidemia del VIRUS SARS CoV2 (COVID-19) ha impactado al campo del Derecho, la principal consecuencia infirió simultáneamente en la administración de justicia, conjuntamente en la restricción del derecho humano de acceso a la justicia, el trabajo digno, la vida libre de violencia para las mujeres, la convivencia entre los progenitores y sus descendientes, así como otros derechos humanos.

El propósito del presente trabajo es analiza la afectación a los derechos humanos que se han visto limitados por esta epidemia, y poder proponer una forma de redefinir la aplicación del derecho en sus diversas ramas ante situaciones futuras.

Palabras clave: Epidemia, Covid-19, Acceso a la Justicia, Violencia de género, DecretoConfinamiento.

${ }^{1}$ Doctora del Programa de Doctora en Derecho de la Universidad Autónoma de Baja California. https://orcid.org/0000-0003-3361-7923

\footnotetext{
2 Alumno del Programa de Maestría en Derecho de la Universidad Autónoma de Baja California. https://orcid.org/0000-0002-6288-7044.
} 
Año 13.

Revista de Investigación

Núm. 34 Especial Tema COVID 19

Académica sin Frontera

https://revistainvestigacionacademicasinfrontera.unison.mx/index.php/RDIASF

Recibido el 19 de marzo de 2020. Dictaminado mediante arbitraje favorablemente 2 de julio de 2020.

\title{
THE COVID-19 AND ITS CONSECUENCES ON THE ADMINISTRATION OF JUSTICE
}

\begin{abstract}
Currently the issue of the SARS CoV2 VIRUS epidemic (COVID-19) has impacted the field of Law, the main consequence simultaneously inferred in the administration of justice, jointly in the restriction of the human right of access to justice, decent work, life free of violence for women, coexistence between parents and their descendants, as well as other human rights.

The purpose of this work is to analyze the effects on human rights that have been limited by this epidemic, and to be able to propose a way to redefine the application of law in its various branches in future situations.
\end{abstract}

Key words: Epidemic, Covid-19, Access to Justice, Gender Violence, DecreeConfinement.

\section{Introducción}

Hablar sobre el impacto que ha generado el VIRUS SARS CoV2 (COVID-19) a la administración de justicia basadas en las decisiones del Ejecutivo Nacional en armonía con la Secretaria de Salud, lleva a la tarea de identificar en primer término los sectores que se han visto más vulnerados al respecto.

Al respecto, el libre ejercicio de la profesión del derecho constituye uno de los sectores cuya función fue paralizada por el virus en cuestión, ya que las primeras medidas de propagación para preservar la salud, fueron evitar el confinamiento en los lugares más 
Año 13.

Núm. 34 Especial Tema COVID 19

Revista de Investigación

Académica sin Frontera

https://revistainvestigacionacademicasinfrontera.unison.mx/index.php/RDIASF

Recibido el 19 de marzo de 2020. Dictaminado mediante arbitraje favorablemente 2 de julio de 2020.

concurridos como los son: juzgados, agencias especializadas, oficinas de gobiernos y todas aquellas que son necesarias para el desempeño laboral y la búsqueda de administración de justicia.

Así pues, la representación jurídica se vio limitada ante este acontecimiento, sustentada en la determinación que el Poder Judicial Federal y Estatal decretó para atender determinados asuntos basados en la constitucionalidad de su actuar, ponderando en derecho humano a la salud frente el derecho humano de acceso e impartición de justicia.

Es por ello que de ahí deriva la importancia y trascendencia del presente trabajo de investigación, lo anterior con el objetivo de poder dar contestación a las interrogantes:

¿Es constitucional la selección de juicios a fin de administrarles justicia en tiempos de pandemia?

¿Cuáles son las consecuencias jurídicas en la administración de justicia que ha traído consigo la contingencia, derivada de la pandemia del COVID-19?

¿Es inconstitucional la omisión de establecer protocolos de actuación en la administración de justicia en casos de eventos naturales, de saludo o de cualquier índole que impidan la presencia física en los recintos judiciales?

\section{Antecedentes históricos y de salud del VIRUS SARS CoV2 y el decreto-confinamiento}

El tema relativo a la pandemia del coronavirus, en lo especifico al VIRUS SARS CoV2, en adelante por sus siglas (COVID-19), es una cuestión que aqueja a los ciudadanos a nivel mundial, este virus ha sido definido por el Fondo de las Naciones Unidas para la Infancia como "una enfermedad infecciosa causada por el coronavirus que se ha descubierto más recientemente (Fondo de las Naciones Unidas para la Infancia, 2020) entendiéndose por este según la Organización Mundial de la Salud, como "una extensa familia de virus que 
Año 13.

Núm. 34 Especial Tema COVID 19

Revista de Investigación

Académica sin Frontera

https://revistainvestigacionacademicasinfrontera.unison.mx/index.php/RDIASF

Recibido el 19 de marzo de 2020. Dictaminado mediante arbitraje favorablemente 2 de julio de 2020.

pueden causar enfermedades tanto en animales como en humanos. Se sabe que varios coronavirus causan infecciones respiratorias que pueden ir desde el resfriado común hasta enfermedades más graves como el síndrome respiratorio de Oriente Medio (MERS) y el síndrome respiratorio agudo severo (SRAS). El coronavirus que se ha descubierto más recientemente causa la enfermedad por coronavirus COVID-19 (Organización Mundial de la Salud, 2019).

Al respecto, se sabe que en diciembre del 2019, en la ciudad de Wuhan de la República Popular China, inicio un brote de neumonía a causa de la enfermedad por el COVID-19, el cual se ha expandido en diversos países, así mismo el 11 de marzo del 2020, la Organización Mundial de la Salud declaro que "el brote del virus COVID-19 es una pandemia, derivado del incremento en el número de casos existentes en los países que han confirmado los mismos, por lo que se consideró como una emergencia de salud pública de relevancia internacional"'( Diario Oficial de la Federación, 2020).

Cuando el brote del virus COVID-19 entro en acción, el Consejo de salubridad, declaro este suceso como emergencia sanitaria "por causa de fuerza mayor a la epidemia de enfermedad generada por el virus SARS-CoV-2 (Covid-19)" (Secretaria de Gobernación, 2020).

A causa de esta epidemia, se empezaron a tomar medidas preventivas a efecto de salvaguardar la integridad física y salud de la población por parte del Gobierno Federal en coordinación con las entidades federativas, es por ello que el 24 de marzo del 2020 se publicó Decreto en el diario oficial de la federación, por el cual se sanciona el Acuerdo por el que se "establecen las medidas preventivas que se deberán implementar para la mitigación y control de los riesgos para la salud que implica la enfermedad por el virus SARS-CoV2 (COVID-19)”,(Diario Oficial de la Federación, 2020) el Ejecutivo Federal Andrés Manuel López Obrador dicto decreto en el diario oficial de la federación en 


\section{Año 13.}

Revista de Investigación

Núm. 34 Especial Tema COVID 19

Académica sin Frontera

https://revistainvestigacionacademicasinfrontera.unison.mx/index.php/RDIASF

Recibido el 19 de marzo de 2020. Dictaminado mediante arbitraje favorablemente 2 de julio de 2020.

fecha 27 de marzo del 2020, por el que se declaran "acciones extraordinarias en las regiones afectadas de todo el territorio nacional en materia de salubridad general para combatir la enfermedad generada por el virus SARS-CoV2 (COVID-19)" (Diario Oficial de la Federación, 2020).Por otra parte, se han publicado diversas medidas de prevención por parte de la Secretaria de Salud, en los cuales se ha ordenado a la población permanezca en casa, ello con el fin de reducir el número de casos infecciosos, de aquí el nombre de la recomendación sanitaria (Quédate en casa), ya que el Estado Mexicano se ha declarado en Estado de emergencia sanitaria, en consecuencia en "El Gobierno del Estado de Baja California anunció que nadie debe salir de su casa si no es para alguna actividad esencial y habrá autoridades revisando que así sea”,(Ángel, 2020) lo anterior no se ha cumplido a cabalidad, ya que gran parte de la población sigue transitando en las calles sin motivo esencial alguno, es el caso de la ciudad de Mexicali, Baja California, lo anterior se ha puesto en evidencia dado el cambio de las medidas coercitivas para poder hacer cumplir tal determinación.

Por ejemplo, la propuesta de reforma al bando de policía y buen gobierno, efectuada por la alcaldesa de Mexicali, debido a que "Baja California ocupa uno de los primeros lugares a nivel nacional con mayor número de casos confirmados de covid-19"(Milenio, 2020), lo cual es evidencia de que no se ha atendido a las recomendaciones de aislamiento denominadas quédate en casa y guarda sana distancia

A manera de evidenciar esa falta de cumplimiento a las medidas de prevención, se tiene el caso de la Ciudad de Mexicali, Baja California, en donde se suspendió una fiesta con música en vivo, luego de que el propietario del inmueble donde se estaba celebrando el evento hiciera caso omiso a las indicaciones por parte de las autoridades municipales, "los oficiales y la policía ecológica tuvieron que intervenir suspendiendo y sancionando al propietario",(Canal 66, 2020) siendo un atentado en contra de la salud, ya que no se está 
Año 13.

Núm. 34 Especial Tema COVID 19

Revista de Investigación

Académica sin Frontera

https://revistainvestigacionacademicasinfrontera.unison.mx/index.php/RDIASF

Recibido el 19 de marzo de 2020. Dictaminado mediante arbitraje favorablemente 2 de julio de 2020.

acatando la orden de guardar la sana distancia que se debe.

\section{Impacto producido por el COVID-19 en el derecho laboral y diversos sectores por motivo del decreto de confinamiento en el Estado mexicano}

El acatamiento a las recomendaciones señaladas anteriormente no ha acontecido en la sociedad ya que sigue habiendo múltiples llamados de atención, amonestaciones por parte de las fuerzas municipales, tras encontrar reuniones o festejos que claramente se debieron haber suspendido tras el fenómeno que se está viviendo a nivel mundial tanto en temas de recreación como temas laborales.

Existen manifestaciones y marchas con motivo de exigencias para que se otorguen las medidas sanitarias adecuadas en el sector productivo, tal es el caso de empresas en la Ciudad de Mexicali, Baja California en donde trabajadores protestaron que "al asistir a laborar de manera normal, exponen al resto de su familia al tener contacto directo con sus compañeros, por lo que ayer decidieron realizar un paro laboral, siendo que han implementado separar los trabajadores entre sí con simples piezas de cartón, lo cual no es higiénico".(Tapia, 2020)

El aislamiento en el que se encuentra en mundo entero a consecuencia de la epidemia sobre el COVID-19, es una situación muy difícil, "el aislamiento social obligatorio decretado por el estado de alarma y de necesidad ante la pandemia, supone una situación novedosa y excepcional",(Clarín, 2020) no obstante que las medidas de confinamiento se impusieron con el objeto de "reducir de forma dramática la tasa de contagios entre la población",(Solis,2020) la cual ha traído una grave repercusión en las familias, tanto en el sector psicológico, económico, educativo, así como en el sector de salud.

Las medidas de confinamiento son oportunas, pero lamentablemente "muchos 


\section{Año 13.}

Revista de Investigación

Núm. 34 Especial Tema COVID 19

Académica sin Frontera

https://revistainvestigacionacademicasinfrontera.unison.mx/index.php/RDIASF

Recibido el 19 de marzo de 2020. Dictaminado mediante arbitraje favorablemente 2 de julio de 2020.

negocios grandes y pequeños sufrirán fuertes afectaciones por el impacto de la parálisis de las actividades económicas, y algunos no volverán a prestar bienes y servicios al público, lo que ocasionaría altos niveles de desempleo",(Senado de la Republica, 2020) por consiguiente, es claro que traerá repercusiones, ya que no se podrá hacer frente a gastos de primera necesidad, lo cual está ocurriendo con las personas que son afectadas por el cierre de sus fuentes de trabajo, recibiendo una parte de su salario, además otras son despedidas por falta de recursos para poder seguir pagando su salario.

Tan solo en "la capital del estado son 16 las empresas que han reportado afectaciones operativas que van desde falta de insumos que son enviados de los países afectados, como ausentismo del personal a causa del pánico que ha generado la circulación del virus"(Gallego y Tapia, 2020), ello sin contar las empresas que son clausuradas a consecuencia de no otorgar las medidas sanitarias para salvaguardar las condiciones de higiene con las que se debe trabajar, se han tomado medidas por parte del Gobierno Federal tales como "la reducción de manera progresiva del 25\% del salario para altos funcionarios, quienes tampoco recibirán aguinaldo",(Villa, Caña y Morales, 2020) con el fin de poder hacer frente al problema económico que ajena a la población mexicana, así mismo señalo que "con la entrega de 3 millones de créditos y la creación de 2 millones de empleos, se protegerá al 70\% de las familias mexicanas”(Youtube,2020).

Por otro lado, el sector educativo se ha visto afectado, se han implementado mecanismos para poder sobrellevar la contingencia, es el caso de la Universidad Autónoma del Estado de Baja California, misma que desde "el lunes 23 de marzo al sábado 18 de abril suspende clases presenciales y activa el Plan de Continuidad Académica”,(Gaceta Uabc, 2020), lo anterior se ha implementado a fin de no mermar la educación de los jóvenes y así poder prevenir un posible atraso en las distintas Facultades universitarias.

El sector salud ende ha sido el más afectado, a pesar de que se tenían expectativas 


\section{Año 13.}

Revista de Investigación

Núm. 34 Especial Tema COVID 19

Académica sin Frontera

https://revistainvestigacionacademicasinfrontera.unison.mx/index.php/RDIASF

Recibido el 19 de marzo de 2020. Dictaminado mediante arbitraje favorablemente 2 de julio de 2020.

de que esto iba a acabar pronto, tal como lo refiero el subsecretario de Prevención y Promoción de la Salud, Hugo López-Gatell, al manifestar "A partir del 18 de mayo casi mil municipios, de los 2 mil 500 del país podrán levantar las medidas confinamiento establecidas como parte de la emergencia sanitaria y regresar a la normalidad",(Martínez, 2020) sin embargo "debido al incremento de casos de covid-19 en el país, autoridades de la Secretaría de Salud informaron hoy del inicio de la Fase 3 por coronavirus en México, lo que indica que habrá una progresión acelerada de contagios",(Milenio,2020) a pesar de ello se señaló que "se mantienen las fechas de posible regreso a las actividades: 18 de mayo para los municipios donde hay baja transmisión y está controlada, así como el 1 de junio para el resto del país"(Liberto,2020).

Actualmente se cuenta aproximadamente con más de 6,297 infectados y 486 muertes en México, tal como se advierte del muestreo realizado por la Secretaria de Salud, tan solo en el Estado de Baja California se cuenta con "538 infectados y 65 muertes"(García, 2020) a la fecha de hoy 21 de abril del 2020, cantidades que son verdaderamente alarmantes ya que se cuenta con la mitad de la cantidad requerida para que se inicie una fase 3 , es decir solo el Estado de Baja California está contribuyendo con la mitad de lo requerido para poder formalizar la fase 3 de la pandemia, que se acaba de dictar, además ello es un indicador de que la contingencia seguirá activa.

Situación de la administración de Justicia a partir del COVID, ¿Es constitucional decretar el cierre de los servicios de acceso a la justicia?

Como consecuencia del COVID-19 y el decreto de confinamiento, se han detectado alza en el tema de violencia en otros países, por ejemplo, en China se han detectado separaciones con motivo de la violencia intrafamiliar, violencia física y psicológica que se vive por la presión del confinamiento al que se está sometido con motivo de la contingencia sanitaria, la Presidenta de la comisión de Derechos de la Mujer e Igualdad de Género del 


\section{Año 13.}

Revista de Investigación

Núm. 34 Especial Tema COVID 19

Académica sin Frontera

https://revistainvestigacionacademicasinfrontera.unison.mx/index.php/RDIASF

Recibido el 19 de marzo de 2020. Dictaminado mediante arbitraje favorablemente 2 de julio de 2020.

Parlamento Europeo refiere que "este periodo es especialmente peligros para las mujeres. Todos nos enfrentamos a importantes riesgos psicológicos debido al aislamiento o la cuarentena, pero las mujeres y a veces también los niños en domicilios no seguros viven una situación particularmente delicada”.(Noticias Parlamento Europeo, 2020).

A consecuencia de lo anterior "El secretario General de la ONU ha llamado la atención para atender la violencia doméstica contra mujeres y niñas acentuada por el confinamiento en casa", (Tapia, 2020) la situación de violencia contra la mujer se ha agravado con motivo del aislamiento impuesto por la pandemia, de acuerdo con el organismo internacional, "en China, las llamadas telefónicas para reportar violencia doméstica se han triplicado desde el inicio de la pandemia”.(Tapia, 2020)

Por ejemplo, se advierte que en México se ha acrecentado la estadística de violencia familiar, por motivo de la convivencia excesiva a causa del confinamiento; el personal del "Poder Judicial del Estado de México, han atendido 118 casos de violencia familiar",(Jimenez,2020) esto en menos de un mes luego de la cuarentena por COVID-19, en este Estado se siguen atendiendo diversas áreas de la administración de justicia, dado que la cuestión de violencia familiar y las medidas de protección a la misma, estas ameritan una atención que no puede esperar a que la contingencia cese, "las cifras de violencia de género en México ha aumentado, 7 de cada 10 mujeres son víctimas de violencia, hay mayor riesgo de ser víctima de violencia de género en su modalidad de violencia domestica ante el confinamiento y aislamiento",(Sanz,2020) además la atención en asuntos familiares, entregas y recepciones de pensiones alimenticias no pueden posponerse ya que muchas familias dependen de ello.

Se han visto implicadas situaciones de violencia en los hogares, lo cual arroja un desacuerdo por la convivencia prolongada que se sostiene y trae como consecuencia un alza en la demanda de divorcios, sin embargo, para poder resolver las cuestiones antes planteadas 


\section{Año 13.}

Revista de Investigación

Núm. 34 Especial Tema COVID 19

Académica sin Frontera

https://revistainvestigacionacademicasinfrontera.unison.mx/index.php/RDIASF

Recibido el 19 de marzo de 2020. Dictaminado mediante arbitraje favorablemente 2 de julio de 2020.

relativa a los reajustes de las "pensiones alimenticias, convivencias, y divorcio es necesario acudir al órgano jurisdiccional el cual actualmente se encuentra cerrado”, (Carbonell, 2020) o en otra palabras no puede atender estas cuestiones por no ser consideradas como tema de urgencia.

Por otra parte, el gobierno federal advirtió un incremento de peticiones de auxilio, en los hogares, "lo que significa un ambiente más deteriorado y violento en perjuicio de las mujeres, niños y adultos mayores",(Gonzalez,2020) situaciones que hasta el momento se han seguido atendiendo.

En la Ciudad de Mexicali, Baja California se atienden diversas áreas de la administración de justicia, es el caso que el Poder Judicial del Estado ha dictado medidas para que la impartición de justicia no se vea afectada al 100\% por la declaración de emergencia sanitaria que congoja a la población a nivel Nacional, lo anterior aconteció en fecha 17 de marzo del 2020 en donde el Consejo de la Judicatura del Poder Judicial del Estado, aprobó implementar un conjunto de acciones de prevención cuyo objeto atender el problema de salud pública que se empezaba a manifestar en el Estado por el COVID-19, destacando en dicho acuerdo la "suspensión de la obligación de los funcionarios y servidores públicos del Poder Judicial del Estado de Baja California de asistir a sus centro de trabajo, por el periodo comprendido entre el 18 de marzo y 20 de abril de año en curso",(Periódico Oficial del Poder Judicial del Estado, 2020).

Esta suspensión de labores jurisdiccionales se amplía mediante el acuerdo del Consejo de la Judicatura, pasando del 20 de abril al 5 de mayo del 2020 manteniendo vigente el contenido del acuerdo 2.01 antes mencionado, agregando que " los funcionarios y servidores públicos que conformar en Poder Judicial del Estado de Baja California, deben seguir realizando desde su hogar, las tareas inherentes a su función, ello con el principal objeto de poner al día cada una de las áreas de la impartición de justicia y administrativas", 


\section{Año 13.}

Revista de Investigación

Núm. 34 Especial Tema COVID 19

Académica sin Frontera

https://revistainvestigacionacademicasinfrontera.unison.mx/index.php/RDIASF

Recibido el 19 de marzo de 2020. Dictaminado mediante arbitraje favorablemente 2 de julio de 2020.

(Periódico Oficial del Poder Judicial del Estado, 2020) la impartición de justicia no puede cesar, ya que día con día se presentan más y más casos en índole penal-familiar, los cuales no pueden suspender ya que ello conllevaría una afectación los derechos humanos y al núcleo familiar.

Es un hecho público, que el Sistema de Impartición de Justicia no ha cesado al 100\% en cuanto a sus funciones jurisdiccionales, existen guardias en los diversos Juzgados para atender los asuntos de carácter urgente, tales como "pensiones alimenticias, órdenes de protección o solicitudes que se consideren a juicio del órgano jurisdiccional de urgencia por la situación de riesgo en la que se encuentren niños, adolescentes o personas en estado vulnerable”,(Padilla, 2020) lo anterior a razón de que el Consejo de la Judicatura del Poder Judicial del Estado de Baja California reforzara las medidas de salud para hacer frente a la emergencia sanitaria por causa de fuerza mayor.

Lo anterior a efecto de dar cumplimiento con el compromiso de salvaguardar la salud de las personas que asisten a exigir justicia, así como del personal que labora en el órgano jurisdiccional; los magistrados que integran el Tribunal Superior de Justicia siguen laborando en sus salas, los jueces continúan con sus labores elaborando acuerdos y sentencia correspondientes, el compromiso es "continuar con la laboral sin caer en desacato a las disposiciones sanitarias, trabajando en un plan de reactivación paulatino que contenga las medidas sanitarias que permitan no poner en riesgo a todos los que asisten a realizar las diligencias correspondientes".(Ortiz Morales, 2020)

Sin embargo, el confinamiento al que se está sujeto, así como la suspensión parcial de las labores de los órganos jurisdiccionales han traído consecuencias en las convivencias provisionales dictadas para ejercerse en lugares públicos, Juzgados, entre otros, lo cual trae como perjuicio un desequilibrio psicológico para los menores; el tema del cobro de las pensiones alimenticias también ha sufrido cambios, ya que al reducir el salario del deudor 


\section{Año 13.}

Revista de Investigación

Núm. 34 Especial Tema COVID 19

Académica sin Frontera

https://revistainvestigacionacademicasinfrontera.unison.mx/index.php/RDIASF

Recibido el 19 de marzo de 2020. Dictaminado mediante arbitraje favorablemente 2 de julio de 2020.

alimentario como producto de la falta de trabajos y/o la imposición de cierre para las industrias con labores no esenciales, es claro que el deudor alimentario tendrá una reducción en cuanto a su salario y por ende será mayor la carga relativa al pago de pensión para sus menores hijos, ya que aquella se ve mermada por el descuento o falta de pago que se le impone al deudor alimentario.

Relativo al tema de convivencia, en el Estado de México, se decretó el cierre temporal de los centros de convivencia, con el fin de "salvaguardar el interés superior de la niñez y el derecho a la salud de las familias mexiquenses, en concordancia con las acciones dispuestas en el país y la entidad ante la pandemia por COVID-19, que establece como medidas preventivas evitar lugares concurridos y el contacto físico”.

El impacto que ha tenido la pandemia ha mermado el funcionamiento del sistema de justicia, sin embargo, se ha tratado en gran medida por parte de los órganos jurisdiccionales, de atender las cuestiones catalogadas como urgentes, ya que estas ameritan la tutela de diversos derechos humanos con mayor impacto, re agendando las audiencias y/o citaciones no urgentes, mismas que se deberán de atender posterior a la contingencia, pero esto viene hacer un claro ejemplo del dicho " la justicia retardada es justicia denegada", (El mexicano, 2020) lo cual constituye una violación a los derechos humanos reconocidos en la Constitución Política de los Estados Unidos Mexicanos.

Existe la Ley Federal de Paz Pública y Suspensión de Derechos y Garantías, Reglamentaria del artículo 29 de la Constitución Política de los Estados Unidos Mexicanos, donde se refiere que la suspensión de garantías es un procedimiento en el que intervienen, en forma conjunta diversas autoridades, a saber: el Ejecutivo federal; los titulares de las secretarías de Estado, de los departamentos administrativos, y de la Procuraduría General de la República; el Congreso de la Unión y en sus recesos la Comisión Permanente del mismo 
Año 13.

Núm. 34 Especial Tema COVID 19

Revista de Investigación

Académica sin Frontera https://revistainvestigacionacademicasinfrontera.unison.mx/index.php/RDIASF

Recibido el 19 de marzo de 2020. Dictaminado mediante arbitraje favorablemente 2 de julio de 2020.

(De Silva, Gustavo, 2008), sin embargo esta se encuentra pendiente de aprobación.

A lo largo de la historia se han suscitado situaciones que ameritan la suspensión de derechos, sin embargo se han tratado de solucionar mediante otras figuras jurídicas y/o reglamentarias como lo es "El Plan de Auxilio a la Población Civil en Casos de Desastre",(Secretaria de la Defensa Nacional, 2019) por sus siglas DN-III-E, mismo que fue implementado por la Secretaria de la Defensa Nacional para coadyuvar en situaciones de emergencia, así también la Ley General de Salud contempla otras medidas para hacer frente a circunstancias graves por ejemplo las emergencias sanitarias tal como ocurrió durante el 2010 relativo al tema de la influenza AH1N1, durante este suceso el presidente Felipe Calderón emitió un decreto de emergencia el cual no se encontraba fundamentado en el artículo 29 constitucional si no en la Ley General de Salud, a partir de la reforma constitucional de junio del 2011 se prevé una regulación más extensa en la cual se prohíbe que ciertos derechos puedan ser derogados o afectados por una suspensión de garantías.

El artículo constitucional multicitado también plasma la palabra restricción de derechos, lo que puede interpretarse como el anexo de condiciones para el ejercicio de algún Derecho Humano como es el caso del derecho a libertad, el derecho a la libertad de expresión, sin embargo, esta idea se encuentra fuera de lo que el legislador quiso decir al redactar el artículo 29 constitucional.

Actualmente no se encuentra decretada una suspensión y/o restricción de derechos humanos a nivel constitucional en México, lo cual presume una violación de los derechos humanos reconocidos en la Carta Magna, dado que no se han seguido las formalidades prescritas por la Constitución Federal para hacer valida dicha suspensión, si bien es cierto la pandemia pudiere entrar en los casos de excepción a la suspensión antes señalada, la misma 
Año 13.

Núm. 34 Especial Tema COVID 19

Revista de Investigación

Académica sin Frontera

https://revistainvestigacionacademicasinfrontera.unison.mx/index.php/RDIASF

Recibido el 19 de marzo de 2020. Dictaminado mediante arbitraje favorablemente 2 de julio de 2020.

no se ha efectuado tal como se prevé en el ordenamiento antes mencionado.

\section{Diferencias entre suspensión de derechos humanos y declaratoria de emergencia} sanitaria

La figura de la suspensión o restricción de derechos humanos, la cual se encuentra prevista en el numeral 29 de la Constitución Política de los Estados Unidos Mexicanos, cuenta con una serie de candados que tienen por objeto limitar el riesgo de que se trate de un acto autoritario por parte del Ejecutivo Nacional, más tarde con la reforma en materia de derechos humanos del año 2011 fue que se estableció una distinción entre lo que se entendía por restricción y suspensión de derechos humanos de tal manera, que "la suspensión se entiende como si de manera absoluta se perdiera de forma temporal determinado derecho humano considerado obstáculo para hacer frente a una situación de emergencia; la restricción, por su parte, no implica una pérdida, sino que se imponen ciertos límites a su ejercicio que permite una gradualidad”.'(Zeind, 2020)

Esta suspensión conlleva limitantes como antes se refirió, existe un catálogo de Derechos Humanos que no pueden suspenderse o restringirse, tales como la vida, la integridad personal, la no discriminación, entre otros.

Por otra parte, la restricción o suspensión cuenta con elementos adicionales para su justificación, ya que debe ser proporcional al peligro a que se hace frente, los decretos que recaigan como consecuencia de la suspensión deberán ser revisados de manera oficiosa por la Suprema Corte de Justicia de la Nación.

Un ejemplo histórico de nuestro país en el cual se aplicó materialmente restricciones a derechos humanos con el fin de atender una emergencia sanitaria de carácter transitoria sin tomar en cuenta lo dispuesto por el artículo 29 de la Constitución Federal, fue la propagación 


\section{Año 13.}

Revista de Investigación

Núm. 34 Especial Tema COVID 19

Académica sin Frontera

https://revistainvestigacionacademicasinfrontera.unison.mx/index.php/RDIASF

Recibido el 19 de marzo de 2020. Dictaminado mediante arbitraje favorablemente 2 de julio de 2020.

de la influenza humana AH1N1, la cual tuvo lugar en el año 2009, situaciones como "la epidemia H1N1 obligan a las autoridades de salud a tomar medidas que en algunos casos pueden vulnerar los derechos individuales",(Ugartem Gil, 2009: 415) con motivo de preservar el bien común, en este caso la salud pública.

Esta facultad consagrada en la Constitución Política de los Estados Unidos Mexicanos en su numeral 73 fracción XVI prescribe que "en caso de epidemias de carácter grave o peligro de invasión de enfermedades exóticas en el país, la Secretaría de Salud tendrá obligación de dictar inmediatamente las medidas preventivas indispensables, a reserva de ser después sancionadas por el Presidente de la República”(Cpeum,1917).

Cabe destacar que esas medidas adoptadas por la Secretaria de salud ejecutadas por el Ejecutivo Nacional son diversas a las previstas en el artículo 29 de la Constitución antes mencionada, ya que son emergentes de una cuestión sanitaria.

El COVID-19 fue catalogado como emergencia sanitaria internacional por la Organización Mundial de la Salud, ya que este virus cumple con los requisitos, siendo que "el brote de una enfermedad afecta a más de un país y se requiere una estrategia coordinada internacionalmente para enfrentarlo. Además, debe tener un impacto serio en la salud pública y ser inusual e inesperado",(Organización Mundial de la Salud, 2020); cabe señalar que solo existen 5 casos documentados en donde se haya aplicado este criterio, siendo los asuntos de relevancia internacional la "Gripe porcina, Ebola en áfrica occidental, Poliomielitis, Zika, Ebola en la república del Congo", (Organización Mundial de la Salud, 2020) en consecuencia estos son los únicos precedentes en donde se ha declarado cuestión de emergencia sanitaria internacional por parte de la Organización Mundial de la Salud. 
Año 13.

Núm. 34 Especial Tema COVID 19

Revista de Investigación

Académica sin Frontera

https://revistainvestigacionacademicasinfrontera.unison.mx/index.php/RDIASF

Recibido el 19 de marzo de 2020. Dictaminado mediante arbitraje favorablemente 2 de julio de 2020.

En consecuencia, se puede inferir en la suspensión de derechos humanos y declaratoria de emergencia sanitaria con llevan las mismas finalidades y se decretan en casos excepcionales pudiendo tener los mismos efectos, lo que presupone que estas figuras son sinónimos.

\section{Emergencia sanitaria en México a causa del COVID-19 ¿Necesidad de declarar Estado de excepción?}

La institucionalidad del Estado de excepción, puede definirse como "instrumento jurídico para regular eventos graves de conflictos internos o externos”, (Derechos Ecuador, 2009) se encuentra previsto con el fin de superar cuestiones de peligro o casos extremos de seguridad.

La emergencia sanitaria a causa del COVID-19 ha sido un tema polémico, se ha elevado a categoría internacional, por ser un problema que aqueja a todo el mundo, además que derivado de este tipo de emergencia, algunos Estados se han visto obligados a emitir recomendaciones y restricciones al ejercicio de ciertos derechos humanos, tales como el libre tránsito, la asociación, la libertad de expresión entre otros, sin embargo como se ha observado ha sido ajeno a la facultad que se le confiere al Ejecutivo Nacional, en la Constitución Federal en concordancia con el compromiso del Estado Mexicano por haber ratificado la Convención Americana de los Derechos Humanos.

El numeral 27 de la Convención antes mencionada se considera norma reglamentaria del artículo 29 Constitucional, dado no existe en la actualidad ordenamiento mexicano reglamentario del articulo 29 antes mencionado que contemple la suspensión de derechos humanos con las limitantes correspondientes. 


\section{Año 13.}

Revista de Investigación

Núm. 34 Especial Tema COVID 19

Académica sin Frontera

https://revistainvestigacionacademicasinfrontera.unison.mx/index.php/RDIASF

Recibido el 19 de marzo de 2020. Dictaminado mediante arbitraje favorablemente 2 de julio de 2020.

La suspensión de las garantías es considerada una medida extrema, es por ello que se encuentra prevista con las limitantes ya desarrolladas en el presente documento, pero puede ser en algunas ocasiones "el único medio para atender a situaciones de emergencia pública y preservar los valores superiores de la sociedad democrática”, (Salazar Ugarte, 2013) sin embargo no se puede prever, que consecuencias podría conllevar si se dictara una suspensión de los derechos humanos con las formalidades exigidas para ello.

Se debe tomar en cuenta todas las opciones que existan antes de emitir la suspensión de derechos humanos, ya que recordemos que la reforma constitución en materia de derechos humanos del junio del 2011 trajo consigo un nuevo panorama para la interpretación del alcance de los derechos humanos, debiendo optar por aquella que tutele en mayor medida el derecho humano en cuestión "e inversamente, a la norma o a la interpretación más restringida cuando se trata de establecer restricciones permanentes al ejercicio de los derechos o de su suspensión extraordinaria"(Méndez Silva, 2014), pues ante la existencia de varias posibilidades de solución a un mismo problema, obliga a optar por la que protege en términos más amplios.

Las funciones principales de la declaratoria del Estado son:

A) “La disolución o limitación del principio de división de poderes,

B) Atribución de facultades especial al titular del poder ejecutivo,

C) Dentro de esas facultades destaca la atribución de expedir normas generales,

D) La limitación o suspensión de determinados derechos humanos,

E) La limitación o suspensión de las garantías de determinados derechos humanos". (Salazar Ugarte, 2013)

En estas funciones se refleja el equilibrio que existe entre dos principios básicos del constitucionalismo presentes en este supuesto, la separación de los poderes y su control mutuo, actualmente a la fecha, no se ha considerado necesario optar por establecer 


\section{Año 13.}

Revista de Investigación

Núm. 34 Especial Tema COVID 19

Académica sin Frontera

https://revistainvestigacionacademicasinfrontera.unison.mx/index.php/RDIASF

Recibido el 19 de marzo de 2020. Dictaminado mediante arbitraje favorablemente 2 de julio de 2020.

constitucionalmente el Estado de excepción ya que se han implementado otras medidas menos restrictivas, igualmente efectivas y más favorables para los ciudadanos.

\section{Conclusiones}

Primera. - La pandemia del VIRUS SARS CoV2 ha significado varias cosas para el Estado mexicano, grandes pérdidas humanas, así como evidencia de que el sistema de justicia no está preparado para soportar situaciones extremas derivadas de confinamientos.

Segunda. - El confinamiento forzoso a que está sujeto todo el mundo, en especial el Estado mexicano, ha aumentado el índice de casos de violencia de género en su modalidad de violencia doméstica, lo anterior es así por la convivencia forzosa a la que se está sujeto.

Tercera. - Dentro del Estado mexicano, no se ha decretado formalmente una suspensión de derechos con rango constitucional, dado que no se han cumplido los requisitos previstos por la propia constitución federal, por lo que no se puede hablar de un Estado de excepción existente en Baja California.

Cuarta. - El confinamiento ha traigo consigo una gran merma tanto en el sector productivo, comercial, así como en la administración de justicia, violentando de manera irrevertible situaciones jurídicas.

Quinta. - La suspensión total o parcial del sistema de justicia es inconstitucional, ya que no se han dictado las medidas idóneas para poder prever la afectación en la administración y acceso a la justicia para los ciudadanos. 
Año 13.

Núm. 34 Especial Tema COVID 19

Revista de Investigación

Académica sin Frontera

https://revistainvestigacionacademicasinfrontera.unison.mx/index.php/RDIASF

Recibido el 19 de marzo de 2020. Dictaminado mediante arbitraje favorablemente 2 de julio de 2020.

\section{Referencias}

1. Presidencia de la República Dominicana y la Organización Mundial de la Salud. (2020). 35 Preguntas y respuestas sobre el coronavirus y falsos rumores. República Dominicana. UNICEF.https://www.unicef.org/dominicanrepublic/informes/35preguntas-y-respuestas-sobre-el-coronavirus-y-falsos-rumores.

2. Organización Mundial de la Salud. (2020). Preguntas y respuestas sobre la enfermedad por coronavirus (Covid-19). Organización Mundial de la Salud. https://www.who.int/es/emergencies/diseases/novel-coronavirus-2019/advice-forpublic/q-a-coronaviruses.

3. Secretaria de Salud. (2020). Acuerdo suspensión de labores no indispensables en la administración pública federal. Diario Oficial de la Federación. en https://www.business-

humanrights.org/sites/default/files/documents/ACUERDO $\% 20$ Suspensio\%CC\%81n $\%$ 20de\%20labores\%20no\%20indispendables\%20en\%201a\%20Administracio\%CC $\% 81 \mathrm{n} \% 20 \mathrm{Pu} \% \mathrm{CC} \% 81$ blica\%20Federal\%202.pdf.pdf.pdf.pdf.

4. Secretaria de Gobernación. (2020). Consejo de Salubridad General declara emergencia sanitaria nacional a epidemia por coronavirus COVID-19 https://www.gob.mx/salud/prensa/consejo-de-salubridad-general-declaraemergencia-sanitaria-nacional-a-epidemia-por-coronavirus-covid-19-239301.

5. Secretaria de Gobernación. (2020). Diario Oficial de la Federación. http://www.dof.gob.mx/nota_detalle.php?codigo=5590340\&fecha=24/03/2020.

6. Secretaria de Gobernación. (2020). Diario Oficial de la Federación. https://www.dof.gob.mx/nota_detalle.php?codigo=5590673\&fecha=27/03/2020.

7. Ángel R. (31 de marzo del 2020). ¡Es oficial! México declara emergencia sanitaria por Covid-19. El sol de Tijuana. https://www.elsoldetijuana.com.mx/local/es-oficialmexico-declara-emergencia-sanitaria-por-covid-19-enfermedad-salud-casos5038115.html

8. Milenio. (15 de abril del 2020). Preparan multas contra quienes realicen fiestas en Mexicali. El milenio. https://www.milenio.com/estados/coronavirus-en-mexicali- 
Año 13.

Núm. 34 Especial Tema COVID 19

Revista de Investigación

Académica sin Frontera

https://revistainvestigacionacademicasinfrontera.unison.mx/index.php/RDIASF

Recibido el 19 de marzo de 2020. Dictaminado mediante arbitraje favorablemente 2 de julio de 2020.

preparan-multas-por-realizar-fiestas.

9. Canal 66. (16 de abril del 2020). Suspenden fiesta en plena pandemia. Canal 66. https://www.canal66.tv/policiaca/suspenden-fiesta-en-plena-pandemia.

10. Tapia M. (6 de abril del 2020). Protestan trabajadores de maquiladoras en Mexicali. La voz de la frontera. https://www.lavozdelafrontera.com.mx/local/protestantrabajadores-de-maquiladoras-en-mexicali-5068195.html

11. El Clarín. (16 de abril del 2020). Consecuencias del aislamiento y la soledad por el coronavirus, http://www.clarin.com/viva/consecuencias-aislamiento-soledadcoronavirus_0:oHvsA3T1n.htmll.

12. Solís V. (20 de marzo del 2020). Aislamiento, cuarentena y toque de queda: qué significan estos términos comunes en tiempos de coronavirus. Univisión. https://www.univision.com/local/san-francisco-kdtv/aislamiento-cuarentena-ytoque-de-queda-que-significan-estos-terminos-de-moda-en-tiempos-decoronavirus

13. Senado de la Republica. (2020). PT propone blindaje a economía familiar por efectos de la pandemia COVID-19", Coordinación de comunicación social. http://comunicacion.senado.gob.mx/index.php/informacion/boletines/47958-ptpropone-blindaje-a-economia-familiar-por-efectos-de-la-pandemia-covid-19.html

14. Gallegos E. (14 de marzo del 2020). Covid-19 afecta a 16 industrias en Mexicali. La voz de la frontera. https://www.lavozdelafrontera.com.mx/local/covid-19afecta-a-16-industrias-en-mexicali-4969235.html

15. El universal. (2020). AMLO anuncia 11 medidas para enfrentar crisis por Covid-19 y precios del petróleo. El universal. https://www.eluniversal.com.mx/nacion/amloanuncia-11-medidas-para-enfrentar-crisis-por-covid-19-y-precios-del-petroleo.

16. De silva Gutiérrez, Suspensión de Garantías. Análisis del artículo 29 Constitucional, Revista Mexicana de Derecho Constitucional, Núm 19, 2008, Universidad Nacional Autónoma de México, recuperado el 30 de junio del 2020 en https://revistas.juridicas.unam.mx/index.php/cuestionesconstitucionales/article/view/5845/7736 
Año 13.

Núm. 34 Especial Tema COVID 19

Revista de Investigación

Académica sin Frontera

https://revistainvestigacionacademicasinfrontera.unison.mx/index.php/RDIASF

Recibido el 19 de marzo de 2020. Dictaminado mediante arbitraje favorablemente 2 de julio de 2020.

17. El universal. (22 de abril del 2020). AMLO anuncia plan de rescate económico por Covid-19. https://www.youtube.com/watch?v=9f1CitBywXY.

18. Gaceta UABC. (14 de marzo del 2020). Activa UABC plan de atención de contingencia por coronavirus COVID-19. http://gaceta.uabc.mx/notas/academia/activa-uabc-plan-de-atencion-decontingencia-por-coronavirus-covid-19.

19. Martínez N. (20 de abril del 2020). Salud levantará confinamiento el 18 de mayo en mil municipios. El sol de México. https://www.elsoldemexico.com.mx/mexico/sociedad/salud-hugo-lopez-gatelllevantara-confinamiento-el-18-de-mayo-en-mil-municipios-covid-19-coronavirus5125920.htm

20. Milenio. (23 de abril del 2020). Fase 3 del coronavirus en México: qué es y qué medidas debes tomar. El milenio. https:/www.milenio.com/politica/fase-3coronavirus-mexico-significa-consiste.

21. Aristegui noticias. (2020). Declara México inicio de la Fase 3 del coronavirus. https://aristeguinoticias.com/2104/mexico/declara-mexico-inicio-de-la-fase-3del-coronavirus/.

22. Liberto. (2020). Coronavirus en México, minuto a minuto: infectados y fallecidosHOY martes 21 de abril. https://libero.pe/ocio/1554526-coronavirus-mexicocovid-19-mapa-cdmx-casos-confirmados-infectados-muertes-contagiadospuebla-ultimas-noticias-conferencia-secretaria-salud-martes-21-abril-2020.

23. García R. (16 de abril del 2020). Crece a 65 muertos y 538 casos confirmados de Covid-19 en BC. $\quad$ El imparcial. https://www.elimparcial.com/mexicali/mexicali/Crece-a-65-muertos-y-538casos-confirmados-de-Covid-19-en-BC-20200416-0004.html

24. Tapia Palacios P. (28 de abril del 2020). Cuarentena con tu abusador. https://www.forbes.com.mx/cuarentena-con-tu-abusador-la-violencia-de-generoy-el-covid-19/. 
Año 13.

Núm. 34 Especial Tema COVID 19

Revista de Investigación

Académica sin Frontera

ISSN: 2007-8870

https://revistainvestigacionacademicasinfrontera.unison.mx/index.php/RDIASF

Recibido el 19 de marzo de 2020. Dictaminado mediante arbitraje favorablemente 2 de julio de 2020.

25. Jiménez Jacinto R. (27 de abril del 2020). Atienden 5 casos diarios por violencia familiar durante cuarentena en Edomex. El Universal. https://www.eluniversal.com.mx/metropoli/edomex/atienden-5-casos-diariospor-violencia-familiar-durante-cuarentena-en-edomex.

26. Sanz Luke Belem ( 28 de abril del 2020). expansión de covid-19 genera efectos particulares en mujeres: Sanz. Aristegui noticias. https://aristeguinoticias.com/2804/mexico/expansion-de-covid-19-generaefectos-particulares-en-mujeres-sanz-video/.

27. Infobae. (26 de abril del 2020). En plena pandemia de Covid-19, se disparan las llamadas por violencia doméstica en México. Infobae. https://www.infobae.com/america/mexico/2020/04/26/en-plena-pandemia-decovid-19-se-disparan-las-llamadas-por-violencia-domestica-en-mexico/.

28. Poder Judicial del Estado. (2020, abril). Periódico Oficial del Poder Judicial del Estado. https://www.poder-judicial-bc.gob.mx/

29. Poder Judicial del Estado. (2020, abril). Periódico Oficial del Poder Judicial del Estado.

http://www.pjbc.gob.mx/pdfs/acuerdo6may.pdf.

30. Padilla E. (15 de abril del 2020). PJBC amplía suspensión de labores ante Covid19. El imparcial. https://www.elimparcial.com/mexicali/mexicali/PJBC-ampliasuspension-de-labores-ante-Covid-19-20200415-0012.html.

31. Ortiz Morales S. (20 de abril del 2020). Poder Judicial del Estado de Baja California. http://pjbc.gob.mx/videocovid.html.

32. Miguel Carbonell. (12 de abril del 2020). Los abogados durante la pandemia. https://www.youtube.com/watch?v=0Q36GyYh26o.

33. El mexicano. (28 de abril del 2020). Respalda Molina Magaña suspensión de actividades en juzgados estatales por la pandemia. https://www.elmexicano.com.mx/estatal/respalda-molina-magana-suspension-de-actividades-enjuzgados-estatales-por-la-pandemia/2056885 
Año 13.

Núm. 34 Especial Tema COVID 19

Revista de Investigación

Académica sin Frontera

ISSN: 2007-8870

https://revistainvestigacionacademicasinfrontera.unison.mx/index.php/RDIASF

Recibido el 19 de marzo de 2020. Dictaminado mediante arbitraje favorablemente 2 de julio de 2020.

34. Gobierno de México. (1 de mayo del 2019). La Secretaría de la Defensa Nacional estableció el Plan de Auxilio a la Población Civil en Casos de Desastre, denominado PLAN DN-III-E. Secretaria de la Defensa Nacional. https://www.gob.mx/sedena/acciones-y-programas/que-es-el-plan-dn-iii-e.

35. Cerda Guzmán C. (2017). Los derechos fundamentales y la lucha contra el terrorismo: Francia bajo estado de emergencia. Revista derecho constitucional europeo. https://normasapa.com/como-referenciar-articulos-de-periodico/.

36. Zeind Chávez M. (18 de marzo del 2020). suspensión de derechos o declaratoria de emergencia sanitaria, ¿Cuál es la vía idónea para enfrentar el Covid-19? . Nexos el juego de la Suprema Corte. https://eljuegodelacorte.nexos.com.mx/?p=11192

37. Cesar A. Ugarte- Gil. (30 de septiembre del 2009). Nueva influenza A (H1N1): medidas de control y sus efectos en los derechos humanos. Revista Peruana de Medicina Experimental $y \quad$ Salud Publica. http://www.scielo.org.pe/scielo.php?script=sci_arttext\&pid=S172646342009000300027\&lng=es\&tlng=es.

38. Constitución Política de los Estados Unidos Mexicanos. Diario oficial de la Federación. México. 5 de febrero de 1917.

39. Organización Mundial de la Salud. (31 de enero del 2020). OMS: ¿Qué es una emergencia sanitaria internacional? https://www.dw.com/es/oms-qu\%C3\%A9-es-unaemergencia-sanitaria-internacional/a-52217051.

40. Pedro Salazar Ugarte. (2013). La desconocida historia de la mariguana en México. https://archivos.juridicas.unam.mx/www/bjv/libros/8/3567/13.pdf

41. Méndez Silva R. (2014). La reforma constitucional sobre derechos humanos: Una guía conceptual. Boletín mexicano de derecho comparado. http://www.scielo.org.mx/scielo.php?script=sci_arttext\&pid=S0041$86332014000300014 \& \operatorname{lng}=\mathrm{es} \& \ln \mathrm{ln}=\mathrm{es}$.

42. Organización Mundial de la Salud. (2020). Preguntas y respuestas sobre la enfermedad por coronavirus (Covid-19). Organización Mundial de la Salud. https://www.who.int/es/emergencies/diseases/novel-coronavirus-2019/advice-forpublic/q-a-coronaviruses. 
Año 13.

a de Investigación

Núm. 34 Especial Tema COVID 19

Académica sin Frontera

https://revistainvestigacionacademicasinfrontera.unison.mx/index.php/RDIASF

Recibido el 19 de marzo de 2020. Dictaminado mediante arbitraje favorablemente 2 de julio de 2020.

\section{Directorio Institucional}

Dr. Enrique Fernando Velázquez Contreras

Rector

Dr. Ramón Enrique Robles Zepeda

Secretario General Académico

Dra. Rosa María Montesinos Cisneros

Secretaria General Administrativa

Dr. Rodolfo Basurto Álvarez

Director de Vinculación y Difusión

Dra. Adriana Leticia Navarro Verdugo

Vicerrectora de la Unidad Regional Sur

Dr. Ernesto Clark Valenzuela

Director de la División de Ciencias Económicas y Sociales

Dr. Francisco Espinoza Morales

Secretario de la División de Ciencias Económico y Sociales

Dra. Leticia María González Velásquez

Jefe del Departamento de Ciencias Económico Administrativas

Dra. Lidia Amalia Zallas Esquer

Jefe de Departamento de Ciencias Sociales 
Año 13.

Revista de Investigación Académica sin Frontera

Núm. 34 Especial Tema COVID 19

ISSN: 2007-8870

https://revistainvestigacionacademicasinfrontera.unison.mx/index.php/RDIASF

Recibido el 19 de marzo de 2020. Dictaminado mediante arbitraje favorablemente 2 de julio de 2020.

\section{Comité Directivo}

\section{Editor Responsable}

Dr. Francisco Espinoza Morales

\section{Directora}

Dra. Leticia María González Velásquez

\section{Subdirector}

Dr. Javier Carreón Guillen

\section{Editor Científico}

Dr. Cruz García Lirios

\section{Master Gráfico}

M.T.I. Francisco Alan Espinoza Zallas

Nos complace anunciar que su diario, "Academic Research Journal Withoutborders" (ISSN/EISSN 2007-8870) fue evaluado positivamente en la indexación Citefactor, ahora la página de la revista está disponible en línea, en caso de cualquier problema.

Journals Master | International Innovative Journal Impact Factor (IIJIF)

Red Latinoamericana de revistas Académicas en Ciencias Sociales y Humanidades
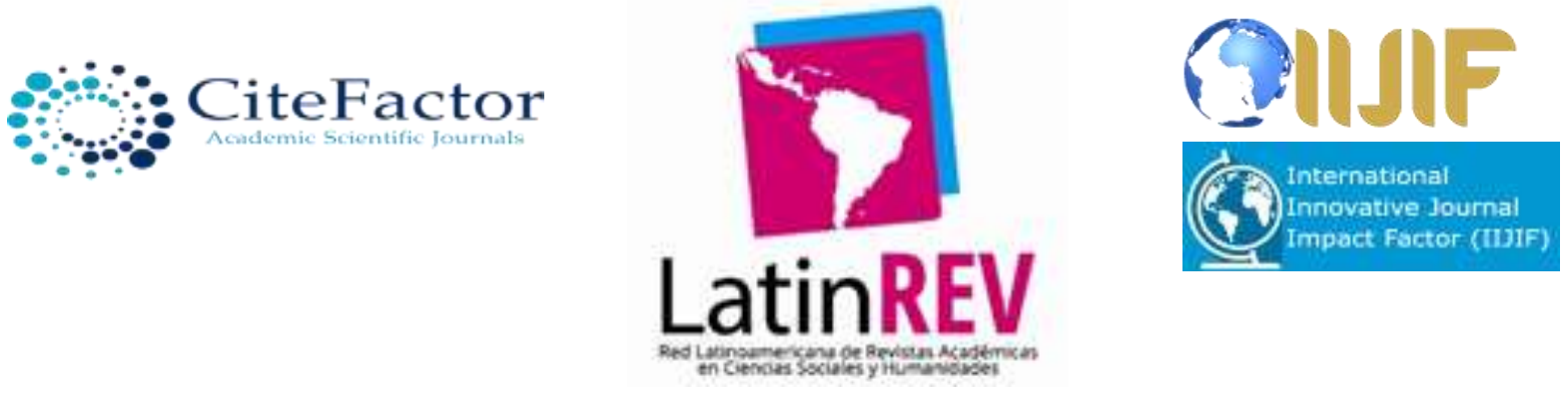
Año 13.

de Investigación

Núm. 34 Especial Tema COVID 19

Académica sin Frontera

https://revistainvestigacionacademicasinfrontera.unison.mx/index.php/RDIASF

Recibido el 19 de marzo de 2020. Dictaminado mediante arbitraje favorablemente 2 de julio de 2020.

\section{Comité editorial}

Dra. Angélica María Rascón Larios

Universidad de Sonora. México

Dra. María del Rosario Molina González

Universidad de Sonora

Dra. Francisca Elena Rochin Wong

Universidad de Sonora. México

Dra. Lidia Amalia Zallas Esquer

Universidad de Sonora. México

Dra. Beatriz Llamas Arechiga

Universidad de Sonora. México

Dr. Rogelio Barba Álvarez

Universidad de Guadalajara. México

Dra. Rosa María Rincón Ornelas

Universidad de Sonora. México

Dr. Juan Flores Preciado

Universidad de Colima. México

Dr. Amado Olivares Leal. Universidad de Sonora

Universidad de Sonora. México

Dr. Guillermo Velázquez Valadez.

Instituto Politécnico Nacional (IPN) México

Dr. Hugo Nefstalí Padilla Torres.

Universidad Estatal de Sonora. México

Dr. Luis Ramón Moreno Moreno.

Universidad Autónoma de Baja California. México

Dr. Miguel Ángel Vázquez Ruiz.

Universidad de Sonora. México 
Año 13.

Revista de Investigación

Académica sin Frontera

Núm. 34 Especial Tema COVID 19

ISSN: 2007-8870

https://revistainvestigacionacademicasinfrontera.unison.mx/index.php/RDIASF

Recibido el 19 de marzo de 2020. Dictaminado mediante arbitraje favorablemente 2 de julio de 2020.

Dra. Lorena Vélez García.

Universidad Autónoma de Baja California. México

Dra. Pabla Peralta Miranda.

Universidad Simón Bolívar, Barranquilla, Colombia

Mtro. Roberto Espíritu Olmos

Universidad de Colima (FCA Tecomán) Colima

Dr. Héctor Priego Huertas.

Universidad de Colima (FCA Tecomán) Colima

Mtra. María Guadalupe Alvarado Ibarra.

Universidad de Sonora. México.

MSc. Celso Germán Sánchez Zayas

Universidad de Camagüey, Ignacio Agramonte Loynaz, Cuba

Dra. María Luisa Quintero Soto

Universidad Autónoma del Estado de México

Dr. Eyder Bolivar Mojica

Universidad Católica, Luis Amigó, Medellin, Colombia

Revisores de Textos en Inglés

Mtro. Renato Encinas

Mtra. Cecilia Guadalupe Martínez Solano

\section{Comité científico}

Dr. Rosendo Martínez Jiménez. Universidad Autónoma Benito Juárez de Oaxaca.

Dr. Hugo Neftalí Padilla. Universidad Estatal de Sonora

Dra. María Teresa Gaxiola Sánchez. Universidad de Sonora.

Dr. José Cesar Kaplan. Universidad Estatal de Sonora.

Dr. Alfredo Islas Rodríguez. Universidad de Sonora

Frecuencia de publicación: semestral / 2 números por año. 
Año 13.

Núm. 34 Especial Tema COVID 19

Revista de Investigación

Académica sin Frontera https://revistainvestigacionacademicasinfrontera.unison.mx/index.php/RDIASF

Recibido el 19 de marzo de 2020. Dictaminado mediante arbitraje favorablemente 2 de julio de 2020.

Revista de Investigación Académica sin Frontera (RIASF) con (ISSN: 2007-8870) es un interlocutor internacional de acceso abierto revisado diario en línea en el ámbito del de las Ciencias Económicas Administrativas y Sociales. Su objetivo principal es dar a los trabajos de investigación de calidad. Cubre todas las sub-campos de los campos anteriormente mencionados. Proporciona la plataforma a académicos, estudiantes y profesionales. Sólo pública trabajos de investigación y artículos de revisión inicial. Documento presentado debe cumplir con algunos criterios como, debe ser original, inédita y no estén sometidos a ninguna otra revista.

RIASF es una revista arbitrada / Revisión por pares International. Publicamos documentos sobre una variedad de temas, contextos y estrategias de análisis que examinan la relación entre la rápida evolución para la Sociedad y la tecnología del conocimiento.

REVISTA DE INVESTIGACIÓN ACADÉMICA SIN FRONTERA, Año 13, No. 33, Julio - diciembre 2020, es una publicación semestral de investigación científica, editada por la Universidad de Sonora, a través de las División de Ciencias Económicas y Sociales, de la Unidad Regional Sur, Blvd. Lázaro Cárdenas No. 100, Col. Francisco Villa, Navojoa, Sonora, Sonora, México, C.P. 85880. Tel. (642) 42599-54.

https://revistainvestigacionacademicasinfrontera.unison.mx/index.php/RDIASF

revistaacademicasinfrontera@unison.mx.

Editor responsable: Francisco Espinoza Morales. Reserva de Derechos al Uso Exclusivo: 042013-121811323700-203 e ISSN: 2007-8870, ambos otorgados por el Instituto Nacional de Derecho de Autor. Inscrita en el Directorio de LATINDEX, con Núm. De folio 20014, folio único 14590. Responsable de la última actualización de este Número, Unidad Informática de la Universidad de Sonora, fecha de la última modificación, 30 de diciembre 2020, indexada a Cite Factor Academic Scientific Journal y Journals Master (IIJIF) y Red Latinoamericana de Revistas Académicas en Ciencias Sociales y Humanidades, (Latín Rev). Las opiniones expresadas por los autores no necesariamente reflejan la postura del editor de la publicación. Se autoriza la reproducción total o parcial de los contenidos e imágenes en la presente publicación siempre y cuando se cuente con la autorización del editor y se cite plenamente la fuente. 
Revista de Investigación

Núm. 34 Especial Tema COVID 19

Académica sin Frontera

https://revistainvestigacionacademicasinfrontera.unison.mx/index.php/RDIASF

Recibido el 19 de marzo de 2020. Dictaminado mediante arbitraje favorablemente 2 de julio de 2020.

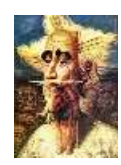

Nos complace anunciar que su diario, "Academic Research Journal Withoutborders" (ISSN/EISSN 2007-8870) fue evaluado positivamente en la indexación Citefactor, ahora la página de la revista está disponible en línea, en caso de cualquier problema.

Journals Master | International Innovative Journal Impact Factor (IIJIF)

\section{Red Latinoamericana de revistas Académicas en Ciencias Sociales y Humanidades}
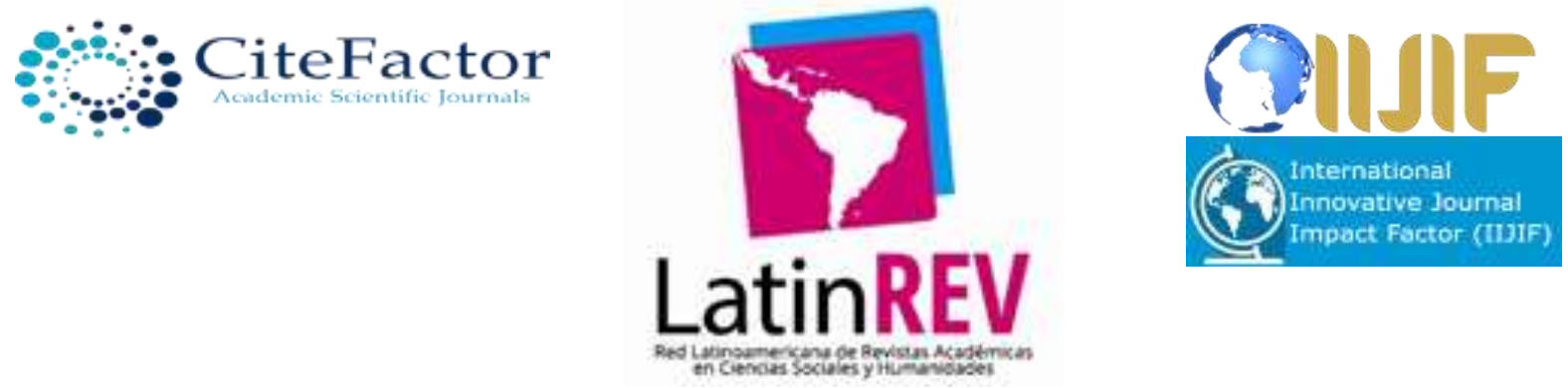

https://www.neliti.com
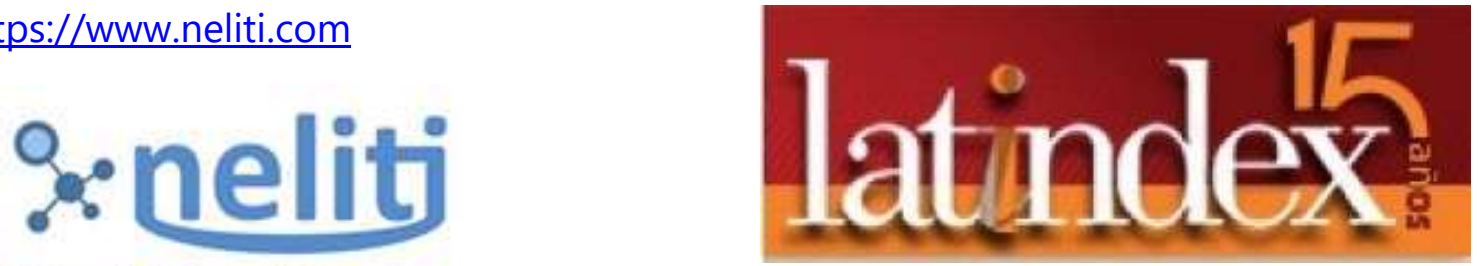

Indonesia's Research Repository
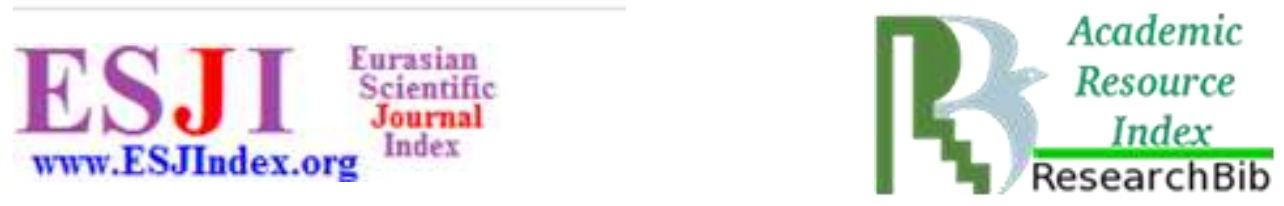